\title{
Corpo e cena em dois documentários de Frederick Wiseman
}

\author{
Body and scene in two documenataries of Frederick Wiseman
}

José Francisco Serafim ${ }^{1}$

\section{Resumo}

Este texto busca trazer algumas considerações acerca de dois documentários de Frederick Wiseman, nos quais são enfatizados o trabalho do corpo que dança e a cena na qual ele esta inserido. As obras documentais $A$ dança. Le ballet de l'Opéra de Paris (2009) e Crazy Horse (2011) apresentam de forma rigorosa o trabalho do corpo do(a) dançarino(a) para se chegar a um resultado considerado excelente pelos coreógrafos, sendo que no caso de $A$ dança, o trabalho do corpo dialoga com o balé clássico e no caso do Crazy Horse com números de dança e striptease de um cabaré parisiense. Wiseman utiliza nos dois filmes o mesmo estilo de montagem vinculado ao cinema direto, de não intervenção na cena filmada. A análise desses dois documentários nos dão pistas de como o audiovisual pode ser uma ferramenta de pesquisas do corpo em cena.

\section{Palavras-chave}

Cinema documentário; corpo; dança; cena; Frederick Wiseman

\begin{abstract}
This text seeks to bring some considerations about two documentaries of Frederick Wiseman, in which are emphasized the work of the body that dances and the scene in which it is inserted. The two documentary The dance. Le ballet de l'Opéra de Paris (2009) and Crazy Horse (2011) present rigorously the work of the body of the dancer in order to arrive at a result considered excellent by the choreographers, and in the case of The dance, the work of the body dialogues with the classic ballet and in the case of Crazy Horse with dance numbers and striptease of a Parisian cabaret. Wiseman uses in the two films the same style of assembly linked to the direct cinema, of non intervention in the filmed scene. The analysis of these two documentaries give us clues about how the audiovisual can be a tool of researches of the body in scene.
\end{abstract}

\section{Keywords}

Documentary film; body; dance; scene; Frederick Wiseman

\footnotetext{
${ }^{1}$ Professor da Faculdade de Comunicação da Universidade Federal da Bahia, Pesquisador do Programa de Pós-Graduação em Comunicação e Cultura Contemporâneas/UFBA. Pós-Doutorado na Universidade Aberta de Lisboa e na Filmuniversität Babelsberg Konrad Wolf (Alemanha). Autor de livros e artigos sobre cinema. Realizador de filmes documentários.
} 
A energia do olhar ele-mesmo...

Georges Didi-Huberman

\section{Introdução}

O documentarista norte-americano Frederick Wiseman tem, desde o final dos anos 1960, realizado uma obra das mais instigantes do gênero documentário, sempre fiel ao seu estilo de filmar vinculado ao movimento do cinema direto. Wiseman traz em seus filmes um olhar observativo face aos temas mais variados, desde seu filme de estréia, que apresenta um presídio manicomial em Massachussets, passando pela instituição escolar, pela policia, pelo hospital entre muitos outros. O diretor busca em seus documentários mostrar sem julgamento de valor o interior de algumas instituições, sobretudo norte-americanas, mas transitou igualmente por outros países: a França, o Panamá, Israel. O diretor de 88 anos realizou em 50 anos de carreira 41 filmes, sendo o último lançado em 2017, Ex Libris. The New York Public Libraries, dedicado às bibliotecas públicas da cidade de Nova Iorque.

Wiseman pode ser hoje considerado uma instituição do cinema documental e tendo em vista a grande importância de sua obra, em 2016, que podemos considerar como sendo o ano de sua consagração enquanto realizador, ele ganhou diversos prêmios importantes, o Oscar pelo conjunto de sua obra e o premio France Culture no Festival de Cannes, neste mesmo ano a Cinemateca Francesa consagrou ao diretor uma retrospectiva do conjunto de seus filmes.

O diretor, que realizou praticamente só documentários ao longo de sua carreira (dirigiu dois filmes de ficção), tem apostado naquilo que denominou-se "o método Wiseman", ou seja, quando este tem um tema que o interessa ele parte para uma breve observação do local e a partir de então, caso a temática o interesse realmente, ele busca as autorizações necessárias para iniciar as filmagens, estas sempre realizadas com uma equipe mínima, sendo que o diretor estará sempre no comando da captação sonora. As filmagens variam entre quatro e sete semanas e quando em posse de uma quantidade de rush que Wiseman considera satisfatória 
ele se isola em seu estúdio e tem então inicio o processo de montagem que raramente é inferior a doze meses. A duração de seus filmes é também muito variável e depende da riqueza do material bruto, sendo que seu filme mais longo, Near death (1989), tem uma duração de seis horas. Adepto do cinema direto, não intervencionista, pois, segundo Jean-Paul Colleyn,

[...] eles [cineastas] querem mostrar a realidade tal qual ela é, sem artifícios prescritos pelo corporativismo profissional: uma realidade crua, em movimento, as vezes mal iluminada, capturada ao acaso, sem tripé, sem preparação do enquadramento, e sem repetição de tomadas. (Colleyn, 2001: 237)

Wiseman não utiliza outro material que não aquele captado durante as filmagens, este sempre com a ausência de depoimentos ou entrevistas, a famosa "mosca na parede". Observamos que essa prática da filmagem com equipe reduzida, sem intervenção do cineasta, utilizando-se de planos longos e com grande quantidade de material bruto faz parte igualmente de um dos aspectos metodológicos da Antropologia Fílmica, ou seja, do uso do material audiovisual no trabalho de pesquisa. Nesse sentido, como é o que ocorre na pesquisa com audiovisual, para Wiseman, o momento da primeira decupagem, é quando tem inicio o processo de montagem, esta fase serve para eliminar boa parte do material captado, inclusive aquele em que as pessoas filmadas olham para a câmera ou conversam com o diretor e/ou equipe. Segundo o diretor praticamente cinqüenta por cento do material bruto é eliminado nesse primeiro momento de contato com o material filmado. Para Claudine de France este tipo de profilmia, relação que as pessoas filmadas estabelecem com a presença da câmera, pode ser considerada discreta ou mesmo neutra. Para a antropóloga-cineasta "as pessoas filmadas se conduzem, segundo todas as aparências, 'como sempre o fazem', parecendo indiferentes à presença do cineasta, pois estão absortas em suas próprias atividades”. (France, 2006: 128). Certamente o cinema de Wiseman se encontra nessa relação de busca de apagamento e discrição da situação profilmica vivenciada durante o momento da filmagem.

Wiseman tem se interessado por temas os mais diversos, mas podemos observar já em seu primeiro documentário, Titicut Follies (1967), realizado em um 
manicômio judicial, uma mise en scène do corpo, este exposto de forma por vezes vergonhosa, ou mesmo impudica. Acompanhamos ao longo de uma hora e quarenta minutos os diversos rituais que acompanham a chegada dos novos internos no manicômio até uma das únicas possibilidades de saída dessa instituição total (E. Goffman, 1987), ou seja, morto em um caixão. Nessa cena que se assemelha a um teatro da tragédia humana, Wiseman, com sua câmera e presença discretas aposta na força da filmagem, desses instantes únicos e não repetidos que fazem parte da experiência humana e este será o estilo que o diretor utilizara em todos seus outros filmes, deixando de lado a única vez em que realizou uma montagem paralela ao mostrar duas situações ocorrendo em tempos diferentes.

Se o corpo em suas mais diversas acepções fará parte de praticamente toda a obra documental do diretor, em alguns filmes este será o tema, a exemplo de Model (1981), sobre uma agência de manequim em NY, Ballet (1995), sobre o American Ballet Theatre, Boxing Gym (2010), sobre uma academia de boxe, e os documentários A dança e Crazy Horse, objeto de análise deste artigo.

\section{O trabalho do corpo: A dança. Le ballet de l'Opéra de Paris (2009)}

O documentário A dança realizado em 2009, apresenta em 158 minutos as diversas facetas do grupo de balé da Ópera de Paris, considerada uma das melhores companhias de dança do mundo. Este documentário foi apresentado e premiado em diversos festivais, inclusive no festival É tudo verdade de 2010. Esta não é a primeira vez que Wiseman filma a dança, já em 1995 ele havia realizado um filme de 2 h50 de duração sobre o American Ballet Theatre. Esta repetição de tema já estava presente na obra do cineasta, por exemplo, em 1969 ele filmou High School, em 1994 ele realizou High School II.

No documentário $A$ dança, acompanharemos as diversas atividades desse grupo de balé, reconhecidamente muito exigente no que concerne à técnica e qualidade coreográfica das bailarinas e bailarinos. Veremos ao longo do filme diversos ensaios de coreografias que estavam sendo preparadas no momento da filmagem, estas vão do clássico Romeu e Julieta ao contemporâneo, como exemplifica a coreografia do finlandês Mats Ek, A casa de Bernarda, o que certamente exige 
do corpo de baile uma enorme dose de ensaios a fim de que possam estar aptos a dançar as diversas coreografias propostas pela Ópera de Paris. Em certo momento do filme veremos uma dançarina se queixar da sua impossibilidade em dançar diversas coreografias, e pede para estar ausente de uma delas, finalizando "Eu não tenho mais 25 anos". Observamos aí o penoso trabalho exigido aos corpos dos membros da companhia. É preciso ser perfeito, estar na afinação correta seja numa coreografia solo, dueto ou em conjunto e tudo sob a supervisão dos diversos coreógrafos e professores. Há aqui um nome a zelar, estar nesse lugar não é para “qualquer dançarino(a)", passa-se por um rigoroso concurso de entrada para a Escola de dança da Ópera de Paris que formara os futuros membros da companhia. Há igualmente uma rígida hierarquia entre os diversos membros dessa equipe, tanto entre os dançarino(a)s, coreógrafo(a)s e professores, como igualmente entre os membros da equipe administrativa.

São essas diversas situações que nos são apresentadas no filme de Wiseman, acompanharemos esses momentos, sem inicialmente ter deles uma grande compreensão, pois como observa Sarah Sékaly,

[...] esta transparência da câmera gera naturalmente um sentimento de imersão no espectador. Como nos filmes de Richard Leacock ou Don Alan Pennebaker, as imagens não são recobertas por uma voz off que orientaria sua compreensão: é ao contrario, a palavra das pessoas filmadas, restituídas na sua duração, que guia o espectador. (Sékaly, 2001, p. 206).

Em $A$ dança, aos poucos perceberemos as diferenças entre as coreografias, a dificuldade de se conseguir o movimento perfeito e no final do filme algumas dessas coreografias ensaiadas exaustivamente na parte inicial do documentário nos serão reveladas em sua versão apresentada para o público, com os figurinos, a música e a iluminação. Esses momentos são mágicos e nos remetem ao trabalho e esforço dos bailarino(a)s para se chegar a esse resultado, harmonioso e belo.

A fim de contextualizar seu filme o diretor inseriu em diversos momentos planos da cidade de Paris, trata-se aqui de planos gerais da cidade que apresentam locais conhecidos de um público em geral, como a Catedral do Sacré-Coeur. Esses planos têm por objetivo igualmente nos dar uma idéia da passagem de tempo 
entre os diversos ensaios que nos são apresentados. Haverá igualmente a inserção de outros planos do interior da Ópera de Paris, poderemos ver então escadas, corredores, janelas entre outros, esses planos têm por função apresentar uma mudança na coreografia que esta sendo ensaiada. Através desses recursos fílmicos compreendemos que diversas coreografias são simultaneamente ensaiadas nos diversos espaços e salas de ensaio da Ópera de Paris.

Outro elemento importante para a compreensão da estrutura do balé serão as diversas sequências que apresentam a diretora do balé, Brigitte Lefèvre, nos diversos contatos que esta tem com outros membros da equipe administrativa, coreógrafos, bailarino(a)s, convidados, mecenas etc. As poucas falas presentes no filme serão sobretudo as dessas sequências, através das quais compreenderemos a grande empresa que é o Balé da Ópera de Paris. Negociam-se novas coreografias, o empréstimo de bailarino(a)s, as diversas viagens que envolvem a apresentação da companhia em várias partes do mundo. Percebe-se, sobretudo o orgulho que a diretora tem em fazer parte dessa companhia e da importância para ela da qualidade do trabalho coreográfico, em certo momento ela dirá "muitos dizem que somos a melhor companhia do mundo, bom, eu diria somos uma das melhores companhias".

A questão hierárquica estará bastante presente igualmente na apresentação de diversos ensaios coreográficos, esses são freqüentemente filmados em plano geral ou de conjunto, câmera frontal face aos espelhos, o corpo do(a) bailarino(a) será em muitos momentos visto através dos espelhos, o que cria por vezes um efeito bastante interessante. Em todas essas seqüências o que predomina é a relação professor-aprendiz. Nesses momentos as únicas vozes que ouvimos são as dos professores ou coreógrafos solicitando uma repetição do movimento, a fim que este fique perfeito. Raramente ouviremos algum comentário ou questionamento do dançarino-aprendiz, este simplesmente acata o comentário do professor e refaz o movimento solicitado. Ouvimos também elogios dos professores quando os aprendizes conseguem chegar a um resultado positivo. Nos filmes de Wiseman os planos são longos, por vezes ultrapassando um minuto, e aqui a longa duração será a regra, observamos então em tempo real, o esforço da bailarina para conse- 
guir chegar a um resultado positivo face a uma demanda por demais exigente do professor. Ao final da coreografia a dançarina cai extenuada, ouvimos sua respiração e observamos o cansaço para se chegar ao resultado esperado pelo coreógrafo. Este ensaio será um dos apresentados pelo diretor na parte final do filme, quando da apresentação pública, nela veremos certamente a beleza, leveza e harmonia dos movimentos dos dois dançarinos, mas a sequência também nos envia a repensar o quão extenuante foi o trabalho e a técnica do corpo necessários para se chegar a esse grau de perfeição. Essas sequências exemplificam um dos elementos fundamentais do cinema de Wiseman, pois abdicando da entrevista ou depoimento, e apostando somente no poder da imagem o espectador vai aos poucos compreendendo os meandros das diversas atividades envolvendo, no caso desse filme, a preparação do corpo dos dançarinos e o grau de dificuldade para as diversas coreografias solicitadas e ao final ele, espectador, esta apto para tirar suas próprias conclusões face ao que lhe foi apresentado.

\section{Mise en scène do corpo feminino, Crazy Horse (2011)}

Após a realização do filme $A$ dança, Wiseman se interessara por outra atividade corporal, o boxe, e realizara Boxing Gym (2010) em uma academia de boxe de Austin no Texas. Em 2011, ao saber que o coreógrafo francês Philippe Découfflé decidiu preparar um espetáculo para o cabaré parisiense Crazy Horse, retornar à Paris para filmar os preparativos da coreografia Désir. Esta será a terceira vez que Wiseman realiza um filme na cidade de Paris, sendo a primeira em 1996, na sala teatral Comédie Française, a segunda na Ópera de Paris (filme analisado anteriormente) e em 2011 no cabaré Crazy Horse. O Crazy Horse faz parte juntamente com o Moulin Rouge e o Lido, do conjunto de locais da capital francesa que apresentam espetáculos de cabaré de luxo para um público local, mas, sobretudo internacional. O diferencial do Crazy Horse em relação aos outros dois cabarés é que neste praticamente só há números femininos nos quais as mulheres vão se despindo ao som de uma trilha musical, mas, sobretudo acompanhadas de um excelente trabalho de iluminação. Outro detalhe importante é que aqui não há, a priori, uma hierarquia das dançarinas, todas apesar de suas individualidades vão se assemelhar através das roupas, perucas, maquiagem e adereços. É como se esti- 
véssemos observando a repetição de um só corpo na sua multiplicidade, o efeito é certamente, impactante. Pois como uma das músicas do espetáculo sublinha "As garotas do Crazy são como soldados. Soldados do exército do erotismo. As garotas do Crazy têm o gosto do champanhe...". E é justamente esse sentido militar de igualdade que será representado em muitas das coreografias do espetáculo. Enfatiza-se em muitas sequências a alta qualidade dos espetáculos do Crazy Horse, e ouvimos frases como "aqui apresentamos o melhor espetáculo de nu feminino chique e sofisticado do mundo". Busca-se, segundo os diretores, trabalhar mais na sugestão para se criar um erotismo sofisticado e não vulgar.

F. Wiseman em entrevista a Emmanuel Dejoux e Cédric Mal relativa ao filme abordara a questão vinculada ao erotismo dos espetáculos enfatizando que eles estão todos centrados na apresentação do corpo feminino e nas aproximações eróticas entre mulheres, não se verá em nenhum espetáculo do Crazy Horse a presença de homens interagindo com as mulheres.

Importante sublinhar que neste que será seu $39^{\circ}$ filme, Wiseman optou pela primeira vez em utilizar equipamento digital. Segundo ele as qualidades do HD se aproximam da película, mas tem deficiências ao nível da iluminação. Conforme seu método de trabalho, após uma rápida inserção junto aos integrantes do cabaré, ele iniciou as filmagens com uma reduzida equipe de filmagem, composta por somente três pessoas: um fotógrafo, o próprio Wiseman na captação sonora e uma assistente. Após quatro semanas de filmagem e 150 horas de material bruto, teve inicio então o processo de montagem, que para este filme durou treze meses. É nesse momento que segundo o diretor o filme começa a ser estruturado, mas para tal é preciso ter um material consistente para iniciar a edição, denominado por Wiseman como "montagem mosaico". Segundo o diretor (entrevista a Dejoux e Mal) "este é o aspecto Las Vegas do trabalho de um documentarista como eu, é preciso arriscar".

Para a realização do documentário Crazy Horse, Wiseman passou em media 12 horas por dia no interior da casa de espetáculos, pois segundo ele, os ensaios tinham inicio às 10 horas e o último espetáculo terminava às $23 \mathrm{~h} 30$. E durante 
esse período filmava poucas horas por dia, muito mais interessado em compreender como se estruturava a casa de espetáculo a fim de conhecer um pouco mais sobre o local. Segundo ele o fato de haver muitas repetições de ensaios e espetáculos públicos facilitou a captação de imagens e sons, já que podia filmar em planos e angulações diferenciados, pensando já no trabalho que seria facilitado no momento da edição.

O documentário apresenta muitos momentos de ensaios coreográficos, sobretudo do espetáculo Désir, mas também apresentações públicas de outros espetáculos do cabaré parisiense. Essas sequências compõem grande parte das duas horas e dez minutos de duração do filme. Observa-se aqui que a câmera dialoga de forma lânguida com aquilo que nos é apresentado, ou seja, diversos números sensuais de mulheres que dançam e em muitos momentos realizam números de striptease, são longos planos-sequência acompanhados de música e de efeitos de iluminação, muitas vezes mostrando partes dos corpos expostos das bailarinas. $\mathrm{Na}$ parte inicial do filme nos é apresentado o ensaio de um dos números do espetáculo Désir, trata-se de uma longa sequência de quatro minutos composta de dois planos, um mais longo de três minutos e o outro de um minuto, nele observamos a forma como se desenvolvem os ensaios no cabaré parisiense. $\mathrm{Na}$ imagem vemos inicialmente uma mulher com um tipo de capacete espacial, ao som de uma música orquestral, que remete a uma ambiência aérea, já que o objeto da coreografia é a nave espacial Sputnik, e ouvimos ao longo da sequência uma voz masculina, a do coreógrafo Philippe Decoufflé, dar instruções daquilo que ele almeja para a coreografia. No inicio há somente uma dançarina que logo mais irá interagir com outra igualmente utilizando um capacete espacial. As instruções do coreógrafo são precisas, mas ao mesmo tempo revelam um aspecto sensual da coreografia presentes no tom de voz do coreógrafo bem como nos termos e palavras utilizadas no ensaio, logo no inicio o coreógrafo diz à dançarina, "atenção ao despertar dos sentidos, você vai se levantar suavemente, é o calor do seu corpo que te faz levantar" e finaliza com um "Yes!". Logo mais ele continua, "de joelhos, tirem os capacetes e curvem o corpo até as nádegas, agora avancem, pronto, se aproximem. Yes!". 
Essas sequências de longos trechos dos espetáculos são interligadas com outras que apresentam as dançarinas em seus camarins ou em momentos de descontração. Em outros momentos acompanharemos as reuniões dos coreógrafos com membros da equipe administrativa e observaremos a grande dificuldade de $\mathrm{P}$. Decoufflé em poder criar e realizar sua coreografia sem que haja ingerência do grupo acionista. Duas sequências bastante elucidativas sobre o Crazy Horse, serão trazidas por duas entrevistas, realizadas por jornalistas, com dois diretores da casa de espetáculo, através delas poderemos compreender como se estrutura o cabaré, a hierarquia presente entre a equipe administrativa e sobretudo os objetivos dos espetáculos do Crazy Horse, enfatizados por ambos diretores como o de mostrar uma idéia de erotismo e de beleza do corpo feminino sem a vulgaridade que muitas vezes acompanha esse tipo de espetáculo.

Na parte final do documentário será apresentada uma longa sequência de seleção de novas dançarinas para compor a equipe do Crazy Horse. As candidatas apresentarão inicialmente sozinhas um número de dança vestidas somente de calcinha e sapato alto, ao som de uma música. Na imagem vemos a apresentação das moças e na banda som os comentários em vos baixa, quase sussurrando, dos coreógrafos pontuando as qualidades e defeitos das candidatas. Logo após essa sessão de apresentações, todas as moças fazem uma fila no palco em frente aos coreógrafos que irão escolher somente oito das dezesseis candidatas. Não nos será apresentado o resultado dessa seleção. Em seguida, já na parte final do filme, assistimos a duas coreografias quase na sua totalidade para então nos ser mostrada a palavra $D E ́ S I R$ e a coreografia que mostra as dançarinas interagirem com as letras da palavra ao mesmo tempo em que cantam uma música. O filme termina da mesma forma que teve inicio, ou seja, com a apresentação de um teatro de sombra mostrando as figuras que se formam das mãos de um homem.

Apesar de selecionado em vários festivais de cinema do mundo (Veneza, Toronto, Nova Iorque, San Sebastian etc.) Crazy Horse não obterá, ao contrário da esmagadora maioria dos filmes de Wiseman, um sucesso de critica, esta estará dividida pontuando o interesse do tema, mas sublinhando que o diretor não conse- 
guiu apresentar a complexidade do trabalho e das relações envolvidas no cotidiano da casa de espetáculo.

\section{Considerações Finais}

Frederick Wiseman tem ao longo desses anos como realizador documentarista realizado uma obra que dialoga entre si tanto ao nível temático quanto formal, já que toda ela será, como foi pontuado acima, realizada sob o prisma estético do cinema direto, não intervencionista no momento da filmagem. Como ele mesmo afirma (entrevista a Dejoux e Mal), "se há algo que eu aprendi ao longo de todos esses anos é o de como realizar um documentário".

Os dois documentários analisados aqui mostram o interesse do cineasta em filmar um corpo que dança, tanto em seus preparativos e ensaios na cena privada quanto em sua apresentação na cena publica. Observa-se, no entanto grandes diferenças na forma de filmar o(a)s bailarino(a)s da Ópera de Paris e as dançarinas do Crazy Horse. No caso do(a)s bailarino(a)s vemos certo rigor no momento da tomada a fim de enfatizar o longo e extenuante trabalho que eles devem efetuar para se chegar a um resultado considerado excelente pelos coreógrafos. Já as bailarinas do Crazy Horse são mostradas praticamente em todo o filme nuas, mesmo quando estão se preparando em seus camarins, e quando dançam, apresentam números coreográficos repletos de grande sensualidade, a câmera aqui coaduna o tema apresentado e se faz mais lânguida e próxima dos corpos, sublinhando o corpo feminino. São duas opções de apresentação bastante diferenciadas, mas que de alguma forma dialogam com os temas que nos são apresentados. Certamente há um trabalho e uma técnica do corpo próprios para os dois tipos de trabalho coreográficos apresentados, e, nesse sentido, a imagem e o som das filmagens irão compor aquilo que mais tarde se tornara o filme que conhecemos com uma duração e forma específicas. Estes quesitos serão, sobretudo, alcançados no processo de montagem que buscará trazer coerência e estrutura as varias horas de material bruto captados durante as filmagens. Apesar de suas diferenças, as duas obras encontram pontos em comum na estrutura do filme ao apresentar tanto sequências de ensaios, apresentações públicas, diversas reuniões administrativas e conversas 
com os coreógrafos. Observa-se também na forma de captação das situações apresentadas e na não intervenção do documentarista durante as filmagens uma aproximação com o uso do material audiovisual numa pesquisa acadêmica que aborde o corpo em cena e suas mises en scène e, sobretudo em um possível diálogo com as metodologias da antropologia fílmica

Ao longo desse mosaico de situações apresentadas compreendemos minimamente como se estruturam tanto o corpo de balé da Ópera de Paris quanto o Crazy Horse, pois Wiseman é partidário de um cinema que aposta no poder da cena filmada sem intervenção. Em uma entrevista para o site Allociné ele ira afirmar "Não gosto do didatismo, não gosto das explicações. Prefiro brincar com as complexidades, ambigüidades. A vida das pessoas é sempre muito complexa e ambígua. A sociologia é sempre didática e repleta de explicações. Eu prefiro a não-explicação de Becket. Essa é interessante e diversificada." Certamente esta frase de Wiseman convém como chave de leitura não somente aos documentários A dança e Crazy Horse, mas a toda sua obra.

\section{Referências}

\section{Bibliográficas}

COLLEYN, Jean Paul. Petites remarques sur 1s moments documentaires d'un grand pays. In Communications. Le parti pris du document, $\mathrm{n}^{\mathrm{o}} 71$. Paris: Seuil, 2001, pp. 233-243.

DEJOUX Emmanuel e MAL Cédric. Entrevista realizada em 7/10/2011 para o site Le Blog Documentaire. http://leblogdocumentaire.fr/frederick-wiseman-unelecon-de-montage-et-de-cinema/. Acesso em 05/01/2018.

DIDI-HUBERMAN, Georges. Aperçues. Paris: Ed. de Minuit, 2018.

DOKHAN, Julien. Entrevista realizada em 26/11/2011 para o site Allociné. http://www.allocine.fr/personne/fichepersonne-9844/interviews/. Acesso em 12/12/2017.

FRANCE, Claudine de. La profilmie, une forme permanente d'artifice en documentaire. In COMOLLI, Annie \& FRANCE, Claudine de. Corps Filmé, Corps Filmant. Nanterre: Publidix, 2006, pp. 117-142.

GOFFMAN, Erving. Manicômios, prisões e conventos. $2^{\mathrm{a}}$ ed. São Paulo: Perspectiva, 1987. 
VIS

Revista do Programa de Pós-graduação em Arte da UnB

SÉKALY, Sarah. À propos de Frederick Wiseman, in Communications. Le parti pris du document, $n^{\circ}$ 71. Paris: Seuil, 2001, pp. 201-224.

\section{Filmográficas}

A dança. Le ballet de l’Opéra de Paris. Frederick Wiseman, 158 min., 2009.

Ballet. Frederick Wiseman, 170 min., 1995.

Boxing Gym. Frederick Wiseman, 91 min., 2010.

Crazy Horse. Frederick Wiseman, 134 min., 2011.

Ex Libris: The New York Public Library. Frederick Wiseman, 197 min., 2017.

High School. Frederick Wiseman, 75 min., 1968.

High School II. Frederick Wiseman, 220 min., 1994.

La Comédie-Française ou L'amour joué. Frederick Wiseman, 223 min., 1996.

Model. Frederick Wiseman. 129 min., 1981.

Near Death. Frederick Wiseman, 358 min., 1989.

Titicut Follies. Frederick Wiseman, 84 min., 1967. 